\title{
Effectiveness of neonatal screening for congenital hypothyroidism
}

\author{
Behrouz Shayestefard $^{1}{ }^{\mathbb{D}},{\text { Naim Sadat } \mathrm{Kia}^{2}}^{\mathbb{D}}$, Masoumeh Alimohammadi $^{(\mathbb{D}}$, Elaheh Ghods $^{4 *(\mathbb{D}}$ \\ ${ }^{1}$ Medical student, Faculty of Medicine, Semnan University of Medical Sciences, Semnan, Iran \\ ${ }^{2}$ Community Medicine Specialist, Social Determinant of Health Research Center, Community and Family Health Department, \\ Semnan University of Medical Sciences, Semnan, Iran \\ ${ }^{3}$ Islamic Azad University, Department of Psychology, Shahrood Branch., Islamic Azad University, Semnan, Iran \\ ${ }^{4}$ Social Determinant of Health Research Center, Community and Family Health Department, Semnan University of Medical \\ Sciences, Semnan, Iran
}

\section{Correspondence to:}

Elaheh Ghods, ghodsemla@

yahoo.com, elaheghods@

semums.ac.ir

Received: 13 Jan. 2021

Accepted: 3 Mar. 2021

ePublished: 1 July 2021

Keywords: Newborn screening, Congenital hypothyroidism, Intelligence quotient

\begin{abstract}
Introduction: Congenital hypothyroidism $(\mathrm{CH})$ is the most common preventable cause of mental retardation. Newborn screening program considerably increases probability of $\mathrm{CH}$ diagnosis and treatment.

Objectives: We aimed to investigate the efficacy of running $\mathrm{CH}$ screening program to maintain normal IQ and physical growth of hypothyroid children in Semnan city.

Patients and Methods: This study was performed on children with definite $\mathrm{CH}$ who were treated and followed up in Semnan health centers. Around 41 children born within 2008-2013 (minimum three years of age) participated. Respective weight and height for age were measured. The Z-scores were calculated based on the WHO-Anthro-Anthro Plus Software. Intelligence Quotient (IQ) was measured with Wechsler Intelligence Score for children-revised (WISC-R). Data analyzed with one-tailed $t$ test compared with age and gender-matched group.

Results: The mean IQ Score in our study group was 90.09 (1.73) with no significant difference compared to healthy counterparts $(P>0.05)$. Z-score for weight and height was -0.46 and -0.45 prospectively and was not significantly different from normal children.

Conclusion: Newborn screening program for $\mathrm{CH}$ has been effective in preventing mental retardation and growth failure.
\end{abstract}

\section{Introduction}

Citation: Behrouz S, Kia NS, Alimohammadi M, Ghods E. Effectiveness of neonatal screening for congenital hypothyroidism. J Prev Epidemiol. 2021;6(1):e05 doi: $10.34172 /$ jpe.2021.05
The worldwide incidence of congenital hypothyroidism $(\mathrm{CH})$ was reported 1:10004000 live births (1-5). Rate of $\mathrm{CH}$ was about seven times higher in Iran based on the national report (6).

The incidence of hypothyroidism varies in countries (2,3,7-9). The trend of the disease in a particular region also varies with time $(2,7,10)$. These differences might be explained by increased survival of preterm- very low birth weight infants (11), several screening guidelines and cut off point for definite diagnosis $(12,13)$, dietary iodine deficiency $(4,10,13)$. Other possible mechanisms were transient hypothyroidism following overuse of iodide-containing solution $(1,14)$, ethnic, racial, tribal differences in thyroid genesis and function (15-17).

Besides, most researches concentrating on investigating the efficacy of $\mathrm{CH}$ screening systems had retrospective design. Therefore, their results affected by confounding factors

\section{Key point}

Congenital hypothyroidism is the most common preventable cause of mental retardation. "Newborn screening program for congenital hypothyroidism" is an effective program in preventing mental retardation based on IQ score (WISC-R) and growth failure according to Z-score of anthropometric indexes in followed up children.

that could not be controlled. Altogether, estimation of $\mathrm{CH}$ prevalence based on such studies could be biased $(10,18)$. Alongside this, a remarkable proportion of the world lack a screening program $(4,5,18)$ or have a poor newborn screening (NBS) coverage or imprecise health information system $(4,19)$.

There are some pieces of evidence about worldwide rising trend of $\mathrm{CH}$ that is too much to justify only by increasing the accuracy and coverage of the NBS program $(1,7)$. Several studies have illustrated higher prevalence of $\mathrm{CH}$ in Iran in comparison to the world $(3,6,8,10)$

Copyright (C) 2021 The Author(s); Published by Society of Diabetic Nephropathy Prevention. This is an open-access article distributed under the terms of the Creative Commons Attribution License (http://creativecommons.org/licenses/by/4.0), which permits unrestricted use, distribution, and reproduction in any medium, provided the original work is properly cited. 
Although the higher ratio of transient hypothyroidism due to iodine deficiency $(17,19)$ and consanguineous parents $(4,20)$ partly explained incidence rate in our country, timely diagnosis and treatment even in transient cases are mandatory to prevent growth and neurodevelopmental defects. If thyroid hormone deficiency remains unrecognized and untreated for more than 2 weeks after birth, can lead to permanent mental retardation, higher risk of other congenital anomalies, metabolic disruptions and consequently severe social and economic burden on the family and the society $(5,6,18,21,22)$.

The main indicator in studying the effectiveness of NBS for $\mathrm{CH}$ is maintaining normal IQ score, preventing borderline IQ score or in other words, preserved IQ score in time interval $(6,21,23)$. Additionally, physical growth of $\mathrm{CH}$ cases remained within normal age and sex matched healthy children $(4,23)$.

\section{Objectives}

Therefore, effectiveness of NBS program for $\mathrm{CH}$ infants as a priority has been investigated in different levels and areas in time trend as a part of the health system evaluation $(18,21,24)$. We aimed to study the efficacy of running $\mathrm{CH}$ screening program to maintain normal IQ and physical growth $\mathrm{CH}$ live births in Semnan city.

\section{Patients and Methods}

\section{Study design}

CH screening Program has been presented worldwide in 1970. Pilot study began in 2004 in our country and 1 year later integrated into national health care system. It reached rapidly to $97 \%$ coverage in both urban and rural regions. This program began in Semnan province in 2007 and is continuing. All neonates (3-5 days of age) have guided to referral screening laboratory. Capillary blood sample is to be taken by heel prick method on filter paper. Infants who have been diagnosed as hypothyroidism after confirmation of screen positive cases by venous blood sample visited by focal point physician and then followed up through health centers in parallel to routine health care.

Optimal treatment is a prerequisite for preventing mental retardation and growth failure. Follow up visit up to 3 years of age could differentiate transient hypothyroidism cases and lead to withdrawal of treatment. Drug therapy of permanent cases persists lifelong.

Wechsler intelligence score for children (WISC) was developed in the 1930s and was first coherently used by researchers in 1949 (25). In 1972, the initial revision of the test and its questions was carried out and then translated and evaluated by Iranian researchers in a package in 1992, revised thereafter and is still used in Iran for children. WISC could be performed from minimum 3 years of age, for preschooler (6-19) and adults (26). Besides, WISC also has been used as health screening for readiness to enter primary school at six years of age. Therefore, applying the same tool facilitates longitudinal studies.
Verbal and functional component of test have been summarized to final IQ score. WISC final score has been classified as average (90-109), low average (80-89), borderline (70-79). We selected 90 as minimum normal and $\leq 70$ as borderline or pathologic IQ. Validity and reliability of Wechsler test in age group of 3 to 6 years (26) and above six years (27) was acceptable.

This study was on children diagnosed with $\mathrm{CH}$ by national NBS. Among treated cases, 41 children over three years of age who were able to participate in WISC were selected. Families were contacted for interview and IQ test through city health centers. The interview with parents and IQ test from children were done after parent's informed consent. Patients with concomitant genetic disease, ADHD, autism and maternal alcoholism were excluded from the study.

The study checklist was filled in through interview with parents and child's documents in health center. It included demographic data, anthropometric indexes at birth, and some probable risk factors such as consanguine families, type of delivery. Meanwhile, a test expert psychologist has achieved the child's intelligence test based on appointment in the same center. The psychologist tried building trust and familiarizing children with the test environment. Wechsler test lasted for 75 minutes and was measured with a chronometer.

Baby height and weight were measured with a digital scale (precision $100 \mathrm{~g}$ ) and non-flexible plastic meter tape (precision $0.5 \mathrm{~cm}$ ), which was the same for all children. Anthropometric indices were analyzed using WHO Anthro Software for up to five years of age and WHO Anthro-plus specific for 6-19 years of age (28).

Z-score for anthropometric indexes, weight for age, height for age, weight for height and BMI present standard deviation from mean children adjusted for age and gender and due to sampling method could be representative of growth rate of children. Comparing growth curve standard based on $\mathrm{Z}$-score is more precise than percentile, because $\mathrm{Z}$-score measures a distance, meanwhile percentile presents a cut off and could be misleading and inappropriate for measuring growth rate (29).

\section{Ethical issues}

The research followed the tenets of the Declaration of Helsinki. The institutional ethical committee at Semnan University of Medical Sciences approved all study protocols (IR.SEMUMS.REC.1394.226). Accordingly, written informed consent was taken from all participants before any intervention. This study was extracted from M.D thesis of Behrouz Shayestefard at this university (Thesis\#1143). Objectives of the study were explained to the parents. They were volunteered to participate in the study by signing informed consent. The participants could leave the project at any time without any interruption in their children's treatment plan. 


\section{Data analysis}

The data was analyzed by SPSS software version 22 . Relationship between variables was calculated by onesample $t$ test, chi-square ( $\chi^{2}$ test), Fisher's exact test. The significance level was considered 5\%.

\section{Results}

Table 1 demonstrates the number of infants born each year 2008-2013 and prevalence of hypothyroidism during these years.

The prevalence of hypothyroidism in these years in our country was 33 in contrast to 46.3 in 10000 live births in Semnan city. Coverage of screening program was $100 \%$ from 2008 up to 2013. We could find about half of them and most of them (45\%) participated in this study.

Table 2 shows the general characteristics of study group. Of 41 confirmed congenital hypothyroid cases, 24 were female $(58.5 \%), 27(65.9 \%)$ delivered by cesarean section and 15 were offspring of consanguineous marriage.

Average time interval between screening and definite diagnosis and treatment was about 22 days. About $66 \%$ (27 parents) were highly and 29\% (12 families) moderately satisfied with screening program and follow-up care. Less than $5 \%$ of caregivers were disappointed with the program.

Treatment was stopped in five patients based on physician order and 36 patients were under therapy at the time of survey.

Mean birth weight and height of study group was 2936 gram and $47 \mathrm{~cm}$ respectively. Mean age, height and weight at the time of study were duly 63.3 months, $108.7 \mathrm{~cm}$ and $18 \mathrm{~kg}$.

Mean IQ Score in our study group was 90.09 (1.73). The mean IQ score of diagnosed cases was not significantly different compared to healthy counterparts $(P>0.05)$. None of studied patients had borderline IQ score $(\leq 70)$. Mean of annual saved IQ score was about 118 (in total 824).
Anthropometric indices Z-score was computed by Anthro and Anthroplus software (28). Table 3 presents Z-scores (standard deviation of anthropometric indices) for weight and height for age and weight to height and body mass index (BMI) at birth and the age of follow-up study.

The last column shows difference between Z-score of all calculated indexes by subtracting birth Z-score from follow-up Z-score of cases. According to this column, $\mathrm{Z}$-score of all indexes were increased in follow-up and these differences were statistically significant in all of the indexes above $(P<0.05)$ except for height for age. Height for age $\mathrm{Z}$-score increment at follow up was the least and not significant overall and based on individual sex group.

Weight for height $\mathrm{Z}$-score is more reliable index of growth rate than BMI in children especially under 5 years of age. A new Z-score difference index was extracted from Z-score differences of BMI and weight for height. We substituted BMI by weight for height Z-score difference when both of them exist (Mean 0.66, SD 1.5). $P$ value of this new index was significant $(P=0.008)$ and remained significant in girls when the data analyzed based on gender $(P=0.027)$. This index was even significantly higher in children with healthy parents compared to the hypothyroid group $(P=0.030)$.

\section{Discussion}

In this study, we evaluated the efficacy of $\mathrm{CH}$ screening program in Semnan city using IQ scores (WISC) and anthropometric indexes of identified and treated patients.

The screening program planning began in 2003 and after a pilot study was integrated into our health care system in 2005 (3). Screening was running in Semnan province since 2007 and its coverage reached $100 \%$ only after several months. The implementation of screening program based on global standards, maintaining social responsibilities for

Table 1. The birth rate and prevalence of congenital hypothyroidism in Semnan city, 2008-2013

\begin{tabular}{|c|c|c|c|c|c|c|c|}
\hline & 2008 & 2009 & 2010 & 2011 & 2012 & 2013 & Total \\
\hline Number of $\mathrm{CH}$ infants identified & 20 & 14 & 21 & 15 & 8 & 13 & 91 \\
\hline Number of participants in our survey & 1 & 7 & 6 & 11 & 3 & 13 & 41 \\
\hline Live birth rate & 3126 & 3056 & 3257 & 3347 & 3057 & 3796 & 19639 \\
\hline Prevalence of $\mathrm{CH}$ per 10000 birth & 64 & 46 & 64.5 & 45 & 26.2 & 34.2 & 46.3 \\
\hline $1 \mathrm{CH}$ per no of live births & 156 & 218 & 155 & 223 & 382 & 292 & 216 \\
\hline
\end{tabular}

$\mathrm{CH}$; congenital hypothyroid.

Table 2. General characteristics of study group (children with positive test for congenital hypothyroidism)

\begin{tabular}{lcc}
\hline Variable & No. (\%) & Mean (SD) \\
\hline Gender & Male: $17(41.5)$ & Female: $24(58.5)$ \\
Birth weight-height & $2936(347) \mathrm{g}$ & $48(2.4) \mathrm{cm}$ \\
Type of delivery & Vaginal: $14(34.1)$ & Cesarean: $27(69.5)$ \\
Consanguineous family & Yes: $15(36.6)$ & No: $26(63.4)$ \\
Hypothyroidism in mother & Yes: $17(41.5)$ & No: 24 (58.5) \\
Child treatment continued & Yes: $36(87.8)$ & No: $5(12.2)$ \\
\hline
\end{tabular}


Table 3. Z-score of anthropometric indexes birth - follow up and Z-score difference

\begin{tabular}{|c|c|c|c|}
\hline Z-score & $\begin{array}{c}\text { Birth } \\
\text { Mean (SD) }\end{array}$ & $\begin{array}{l}\text { Follow-up } \\
\text { Mean (SD) }\end{array}$ & $\begin{array}{c}\text { Z-score Difference } \\
\text { Mean (SD) }\end{array}$ \\
\hline Weight for age & $-0.81(0.8)$ & $-0.46(0.7)$ & $0.35(0.9)^{\mathrm{a}}$ \\
\hline Height for age & $-0.56(1.3)$ & $-0.45(0.7)$ & $0.08(1.4)$ \\
\hline Weight for height & $-0.52(1.7)$ & $-0.05(0.6)$ & $1.33(1.7)^{\mathrm{b}}$ \\
\hline Body mass index & $-0.80(1.3)$ & $-0.21(0.8)$ & $0.61(1.4) \mathrm{C}$ \\
\hline
\end{tabular}

${ }^{\mathrm{a}} P$ value $=0.025,{ }^{\mathrm{b}} P$ value $=0.008,{ }^{\mathrm{c}} P$ value $=0.010$

its monitoring and evaluation is a serious health priority to prevent a major cause of neurodevelopmental disorders. Besides, blood samples and data could be used in other researches. Accordingly, our research is also done to evaluate the performance of the health system to prevent one of the most important causes of preventable mental retardation. Performance of $\mathrm{CH}$ screening system should be proven in all areas and in one area over time.

In the present research, the prevalence of the $\mathrm{CH}$ was 1 : 216 live births and about 2.1 higher than country level (1: 462) (23). $\mathrm{CH}$ incidence fluctuated between 1: 155 to 1 : 382 between 2008 and 2013 (2, 6, 8, 30). The ratio of $\mathrm{CH}$ began from 1: 184 in Mashhad (17), 1:370 in Isfahan (10) to 1: 914 in Tehran (3) in the last two decades. Regardless of how the differences in statistics between cities and in time trend can be argued, the increased prevalence of hypothyroidism in Iran indicates the importance of a global screening program with a comprehensive and standardized evaluation system.

A review of the results of previous studies shows that incidence of $\mathrm{CH}$ in different parts of the world has not been homogenous (4). The prevalence of $\mathrm{CH}$ in EMRO region was 1:2934 live births in Turkey (9), 1:3292 in Saudi Arabia (20). In the eastern region of Asia was 1:1136 in Japan (31), 1:1992 in Taiwan (19), and 1:764 in Mongolia (32). In Europe, from 1:1800 live births in Greek Cypriots (33) to $1: 1970$ in Italy (1).

Increasing worldwide prevalence of $\mathrm{CH}$ could be explained partly by change in the coverage of program $(1,13,22,34)$, methodology $(4,11)$, instrumentation and protocols (TSH lower cut off) $(1,14)$, pregnancies outcome, birth demography $(8,35)$, ethnicity $(5,7)$.

Higher prevalence of screening positive neonates in our city in contrast to country level $(6,8)$ could be explained by complete coverage of program and higher prevalence of transient cases due to factors that affecting the trend $(2,10,17,36)$ such as iodine deficiency $(16)$, geographic area $(10,17)$, ethnicity $(15,31,34)$.

Female predominance in our study (1.4 to 1 ) was in accordance with previous studies $(19,34)$ and opposite to first report by Zeinalzadeh and Talebi from EastAzarbaijan, Iran (36). Interpretation of gender differences in our study with contrasting past studies could not be accurate as our sample size was too small.

Withdrawal of treatment occurred in 5 cases (12.2\%). Based on a review, transient hypothyroidism occurred in $17 \%$ to $40 \%$ of screened cases later in childhood. Although the majority of the transient hypothyroidism cases occurred in third year of life, diagnosis of some cases delayed until seven years of age or more (14). Both transient and permanent cases need to be treated but the underlying cause should be investigated carefully. Comprehensive report including medical geography in parallel to precise case records required to evaluate national and local intellectual and developmental disabilities program.

Several studies in Iran $(3,6,37)$ and other countries have confirmed efficacy of $\mathrm{CH}$ screening program based on average IQ score in follow-up of cases. IQ score of diagnosed cases was not significantly different from minimum IQ score range of normal children (IQ=90-110) as other studies in our country $(6,23,37)$ and worldwide $(18,24,31)$.

Some studies in Iran $(21,36)$ and other countries $(4,24$, 38) have shown lower IQ scores in follow up after 6-12 years but none of them had borderline IQ score (IQ $\leq 70$ ) based on WSCS-R in accordance to our study.

In the present study, saved IQ scores per defined and treated case by screening program were estimated at 20 . Yarahmadi et al have shown even more saved individual IQ Score (36 scores) from national survey in 2006-2007 (6). Main outcome of $\mathrm{CH}$ screening program is normal neurodevelopmental outcome comparing age and sex matched healthy group. Lastly, it could be implied on effectiveness of this screening program on promotion of cognitive and neurodevelopmental health outcomes of congenital hypothyroid cases.

Similar to other studies $(6,21)$, not only mental retardation but also physical growth failure could be prevented by early screening and proper treatment of cases both with transient or permanent hypothyroidism. WHO's growth standards are used for children growth's monitoring. Standard deviations of anthropometric indices (Z-score) of subject group were significantly higher than mean weight - BMI for ages and weight for height standards Z-scores.

In contrast, height for age Z-score changes in follow-up were not statistically meaningful as in other researches. Some studies concluded suboptimal or failed height growth due to time to onset and dose of treatment $(2,37)$

There were some limitations in this study such as changing the contact address of some families, loss to follow up and lacking of health center documents, as well 
as the difficulty in communicating with children.

\section{Conclusion}

Efficacy of the "Newborn screening program for $\mathrm{CH}^{\text {" has }}$ been confirmed in preventing mental retardation based on IQ score (WISC-R) and growth failure according to Z-score of anthropometric indexes in followed up children.

\section{Limitations of the study}

The most important limitation in this study was the change of patients' addresses and also the defects in the records, which were partially eliminated by finding the new addresses of the patients and also supplementary interviews.

\section{Acknowledgments}

We would like to present our sincere thanks to parents for their participation, Medical University Vice Chancellor for Health and City Health Centre team for their considerable support.

\section{Authors' contribution}

EG and MA were the principal investigators of the study. EG, NSK and MA were included in preparing the concept and design. BSh colectted the data. All authors participated in preparing the final draft of the manuscript, revised the manuscript and critically evaluated the intellectual contents. All authors have read and approved the content of the manuscript and confirmed the accuracy or integrity of any part of the work.

\section{Conflicts of interest}

The authors declare that they have no competing interests.

\section{Ethical considerations}

Ethical issues (including plagiarism, data fabrication, double publication) have been completely observed by the authors.

\section{Funding/Support}

This study was supported by the research deputy of Semnan University of Medical Sciences (Grant\# 1143).

\section{References}

1. Olivieri A, Fazzini C, Medda E, Hypothyroidism ISGfC. Multiple factors influencing the incidence of congenital hypothyroidism detected by neonatal screening. Horm Res Paediatr. 2015;83:86-93. doi: 10.1159/000369394.

2. Karimi A, Parvareh M, Moradi G, Nouri B, Allahyari P. The incidence of permanent congenital hypothyroidism: A systematic review and meta-analysis. Chron Dis J. 2019;7:20713. doi:10.22122/cdj.v7i3.411.

3. Ordookhani A, Minniran P, Najafi R, Hedayati M, Azizi F. Congenital hypothyroidism in Iran. Indian J Pediatr. 2003;70:625-8. doi: 10.1007/BF02724251.

4. Jones N-HY, Rose SR. Congenital hypothyroidism. Pediatric Endocrinology. Springer; 2018. p. 371-83.

5. Saran S. Congenital Hypothyroidism. Thyroid Disorders: IntechOpen; 2019.

6. Yarahmadi S, Tabibi SJ, Alimohammadzadeh K, Gooya MM, Mojarrad M, Delgoshaei B. Cost-benefit and effectiveness of newborn screening of congenital hypothyroidism: findings from a National Program in Iran. Indian J Endocrinol Metab. 2010;18:39-43. doi: 10.4103/2230-8210.126528.

7. McGrath N, Hawkes CP, McDonnell CM, Cody D, O'Connell SM, Mayne PD, et al. Incidence of Congenital Hypothyroidism
Over 37 Years in Ireland. Pediatrics. 2018;142:e20181199. doi: 10.1542/peds.2018-1199.

8. Mehran L, Yarahmadi S, Khalili D, Hedayati M, Amouzegar A, Mousapour $\mathrm{P}$, et al. Audit of the congenital hypothyroidism screening program in 15 provinces of Iran. Arch Iran Med. 2019;22:310-7.

9. Simşek E, Karabay M, Safak A, Kocabay K. Congenital hypothyroidism and iodine status in Turkey: a comparison between the data obtained from an epidemiological study in school-aged children and neonatal screening for congenital hypothyroidism in Turkey. Pediatr Endocrinol Rev. 2003;Suppl 2:155-61.

10. Hashemipour M, Hovsepian S, Kelishadi R, Iranpour R, Hadian $R$, Haghighi $S$, et al. Permanent and transient congenital hypothyroidism in Isfahan-Iran. J Med Screen. 2009;16:11-6. doi: 10.1258/jms.2009.008090.

11. Rose SR, Brown RS, Pediatrics AAo, Association AT. Update of newborn screening and therapy for congenital hypothyroidism. Pediatrics. 2006;117:2290-303. doi: 10.1542/peds.20060915.

12. Langham S, Hindmarsh P, Krywawych S, Peters C. Screening for congenital hypothyroidism: comparison of borderline screening cut-off points and the effect on the number of children treated with levothyroxine. Eur Thyroid J. 2013;2:1806. doi: 10.1159/000350039.

13. Ford G, LaFranchi SH. Screening for congenital hypothyroidism: a worldwide view of strategies. Best Pract Res Clin Endocrinol Metab. 2014;28:175-87. doi: 10.1016/j.beem.2013.05.008.

14. Kanike N, Davis A, Shekhawat PS. Transient hypothyroidism in the newborn: to treat or not to treat. Transl Pediatr. 2017;6:34958. doi: 10.21037/tp.2017.09.07.

15. Feuchtbaum L, Carter J, Dowray S, Currier RJ, Lorey F. Birth prevalence of disorders detectable through newborn screening by race/ethnicity. Genet Med. 2012;14:937-45. doi: 10.1038/ gim.2012.76.

16. Ordookhani A, Pearce E, Mirmiran P, Azizi F, Braverman L. Transient congenital hypothyroidism in an iodine-replete area is not related to parental consanguinity, mode of delivery, goitrogens, iodine exposure, or thyrotropin receptor autoantibodies. J Endocrinol Invest. 2008;31:29-34. doi: 10.1007/BF03345563.

17. Baridkazemi S, Bahrami HR, Eftekhari Gol R, Mosa Farkhani E, Hoseini SJ. Investigation of the Risk Factors for Congenital Hypothyroidism in Iran: A Population-Based CaseControl Study. Int J Pediatr. 2019;7:8951-8. doi: 10.22038/ IJP.2018.32945.2909.

18. Léger J. Endocrinology and adolescence: congenital hypothyroidism: a clinical update of long-term outcome in young adults. Eur J Endocrinol. 2015;172:R67-77. doi: 10.1530/EJE-14-0777.

19. Chen J, Lin S, Zeng G, Wang W, Lin Z, Xu C, et al. Epidemiologic characteristics and risk factors for congenital hypothyroidism from 2009 to 2018 in Xiamen, China. Endocr Pract. 2020;26:585-94. doi: 10.4158/EP-2019-0491.

20. Al Jurayyan N, Al Jurayyan R. Congenital hypothyroidism and neonatal screening in Saudi Arabia. Curr Pediatr Res. 2011;16:31-6.

21. Rahmani K, Yarahmadi S, Etemad K, Mehrabi Y, Aghang N, Koosha A, et al. Intelligence Quotient at the age of six years of iranian children with congenital hypothyroidism. Indian Pediatr. 2018;55:121-4.

22. Grosse SD, Van Vliet G. Prevention of intellectual disability through screening for congenital hypothyroidism: how much and at what level? Arch Dis Child. 2011;96:374-9. doi: 10.1136/adc.2010.190280.

23. Mehran L, Khalili D, Yarahmadi S, Delshad H, Mehrabi Y, 
AmouzegarA, et al. Evaluation of the congenital hypothyroidism screening programme in Iran: a 3-year retrospective cohort study. Arch Dis Child Fetal Neonatal Ed. 2019;104:F176-F81. doi: 10.1136/archdischild-2017-313720.

24. Dimitropoulos A, Molinari L, Etter K, Torresani T, LangMuritano M, Jenni OG, et al. Children with congenital hypothyroidism: long-term intellectual outcome after early high-dose treatment. Pediatr Res. 2009;65:242-8. doi: 10.1203/PDR.0b013e31818d2030.

25. Wechsler D. Wechsler Intelligence Scale for Children; manual 1949.

26. Razavieh A, Shahim S. A short form of the Wechsler Preschool and Primary Scale of Intelligence for use in Iran. Psychol ReP. 1992;71:863-6. doi: 10.2466/pr0.1992.71.3.863.

27. Jazayeri AR, Poorshahbaz A. Reliability and validity of Wechsler Intelligence Scale for children third edition (WISCIII) in Iran. J Med Educ. 2003;2:e105004. doi: 10.22037/jme. v2i2.881.

28. Anthro W. WHO Anthro 2005, Beta version Feb 17, 2006: Software for assessing growth and development of the world's children. Geneva: World Health Organization; 2006. Available from: http://www.who.int/childgrowth/software/en/.

29. Mei Z, Grummer-Strawn LM. Standard deviation of anthropometric Z-scores as a data quality assessment tool using the 2006 WHO growth standards: a cross country analysis. Bull World Health Organ. 2007;85:441-8. doi: 10.2471/blt.06.034421.

30. Veisani Y, Sayehmiri K, Rezaeian S, Delpisheh A. Congenital hypothyroidism screening program in iran; a systematic review and metaanalysis. Iran J Pediatr. 2014;24:665.

31. Chen C-Y, Lee K-T, Lee CT-C, Lai W-T, Huang Y-B. Epidemiology and clinical characteristics of congenital hypothyroidism in an Asian population: a nationwide population-based study. J Epidemiol. 2013;23:85-94. doi: 10.2188/jea.je20120113.

32. Padilla CD, Therrell BL Jr; Working Group of the Asia Pacific
Society for Human Genetics on Consolidating Newborn Screening Efforts in the Asia Pacific Region. Consolidating newborn screening efforts in the Asia Pacific region: Networking and shared education. J Community Genet. 2012;3:35-45. doi: 10.1007/s12687-011-0076-7.

33. Skordis $N$, Toumba M, Savva SC, Erakleous E, Topouzi $M$, Vogazianos $M$, et al. High prevalence of congenital hypothyroidism in the Greek Cypriot population: results of the neonatal screening program 1990-2000. J Pediatr Endocrinol Metab. 2005;18:453-61. doi: 10.1515/jpem.2005.18.5.453.

34. Hinton CF, Harris KB, Borgfeld L, Drummond-Borg M, Eaton $\mathrm{R}$, Lorey $\mathrm{F}$, et al. Trends in incidence rates of congenital hypothyroidism related to select demographic factors: data from the United States, California, Massachusetts, New York, and Texas. Pediatrics. 2010;125:S37-47. doi: 10.1542/ peds.2009-1975D.

35. Donaldson $M$, Jones J. Optimising outcome in congenital hypothyroidism; current opinions on best practice in initial assessment and subsequent management. J Clin Res Pediatr Endocrinol. 2013;5:13-22. doi: 10.4274/jcrpe.849.

36. Zeinalzadeh AH, Talebi M. Neonatal screening for congenital hypothyroidism in East Azerbaijan, Iran: the first report. J Med Screen. 2012;19:123-6. doi: 10.1258/jms.2012.012024.

37. Heidari Z, Feizi A, Hashemipour M, Kelishadi R, Amini M. Growth development in children with congenital hypothyroidism: the effect of screening and treatment variables - a comprehensive longitudinal study. Endocrine. 2016;54:448-59. doi: 10.1007/s12020-016-1010-x.

38. Albert BB, Heather N, Derraik JG, Cutfield WS, Wouldes T, Tregurtha S, et al. Neurodevelopmental and body composition outcomes in children with congenital hypothyroidism treated with high-dose initial replacement and close monitoring. J Clin Endocrinol Metab. 2013;98:3663-70. doi: 10.1210/jc.20131903. 